\title{
SISTEM PAKAR PENENTUAN TANAMAN PALAWIJA YANG COCOK TUMBUH PADA SUATU DAERA MENGGUNAKAN ALGORITMA FORWARD CHAINING
}

\author{
Yusran Timur Samuel, Yank Nekmese K. dan Raymond Maulany \\ Fakultas Teknologi Informasi, Universitas Advent Indonesia
}

\begin{abstract}
Abstrak
Para petani sering mendapat kesulitan tentang tanaman palawija apa yang cocok untuk ditanam di area pertanian mereka, Untuk itu dibutuhkan aplikasi sistem pakar yang dapat membantu para petani tersebut untuk menentukan tanaman palawija apa yang dapat ditanam pada lahan pertaniaanya agar dapat bertumbuh menghasilkan secara optimal. Penelitian ini menggunkan metode sistem pakar algoritma forward chaining dengan atribut ketinggian, suhu, ph tanah, curah hujan, intensitas penyinaran, dan kelembaban. Hasil keluaran yang diharapkan adalah informasi tanaman palawija apa yang cocok untuk ditanam di lahan pertanian mereka berdasarkan atribut yang di input. Pada penelitian ini peneliti menggunakan metode System Development Life Cycle (SDLC) dalam merancang aplikasi sistem pakar. Basis pengetahuan yang digunakan pada penelitian ini adalah hasil wawancara dengan pakar ditambah dengan teori yang didapatkan dari berbagai literatur. Pengujian performa dan kinerja aplikasi menggunakan metode blackbox dengan kesimpulan bahwa sistem dapat menjalankan fungsi-fungsinya dengan baik dan sesuai dengan yang diharapkan.
\end{abstract}

Kata kunci: Sistem Pakar, Forward Chaining, Palawija, Daerah tumbuh.

\section{EXPERT SYSTEM FOR DETERMINING THE PLANT OF PALAWIJA WHICH SUITED TO GROW ON A CERTAIN AREA}

\begin{abstract}
Farmers often have Difficulties regarding what crops are suitable for planting in their agricultural areas. For this reason, an expert system application is needed that can help farmers determine what crops can be planted on their agricultural land. This study uses a forward chaininig algorithm expert system method with height attributes, temperature, soil ph, rainfall, Intensity of irradiation, and humidity The expected output is information on what crops are suitable for planting on their agricultural land based on the attributes that are input. In this study researchers used the System Development Life Cycle (SDLC) method in designing expert system applications. The knowledge base used in this study is the result of interviews with experts coup/ed with theories obtained from various literature. Testing the performance and performance of applications using the blackbox method with the conclusion that the system can perform its functions properly and as expected
\end{abstract}

Keywords: Expert System, Forward

\section{Pendahuluan}

Di zaman modern saat ini teknologi informasi telah berkembang pesat dan telah membawa dampak yang besar, kebutuhan akan sistem informasi dan pengolahan data sangatlah penting bagi kehidupan manusia. Perkembangan teknologi informasi juga dapat dirasakan dalam bidang pertanian khususnya bagi para petani. Arus informasi yang semakin cepat dapat mempercepat bahkan mempermudah kinerja kehidupan manusia dalam bidang pertanian khususnya bagi para petani untuk mendapatkan suatu informasi yang dicari. Oleh karena itu para petani atau penanam membutuhkan aplikasi untuk menentukan jenis tanaman palawija apa yang cocok ditanam di daerah atau lahan mereka agar dapat tumbuh dengan optimal berdasarkan karakteristik syarat tumbuh jenis tanaman palawija tersebut. Dengan demikian diharapkan sistem teknologi baru tersebut dapat membantu dan menunjang keefektifan, produktifitas dan efisiensi dalam mendapatkan informasi atau data-data mengenai jenis tanaman palawija yang cocok ditanam di daerah atau lahan tertentu berdasarkan karakteristik syarat tumbuh jenis tanaman palawija tersebut.

Beberapa petani atau penanam sering menanam bibit tanaman palawija, namun mereka tidak mengetahui jenis tanaman palawija yang cocok untuk ditanam di lahan pertanian mereka. Dan akhirnya mereka mendapatkan tamanam yang mereka tanam tidak dapat tumbuh secara optimal, tanaman tumbuh secara tidak normal, batangnya tidak sehat, daunnya tidak lebat, buah yang dihasilkan kecil atau tidak berbuah dan bahkan 
mati karena ketidakcocokan syarat tumbuh dari jenis tanaman palawija yang mereka tanam. Oleh karena itu para petani membutuhkan aplikasi terkait permasalahan yang mereka hadapi karena aplikasi ini merupakan sistem sistem pakar yang berisi pengetahuan dari berbagai sumber tanaman palawija sehingga dapat digunakan untuk mencari tanaman palawija yang cocok untuk ditanam.

Menurut Hasugian dalam A. Sundawa (2018:7), Aplikasi diambil dari kata application yaitu bentuk benda dari kata kerja to apply yang dalam bahasa Indonesia berarti pengolah. Secara istilah aplikasi merupakan subkelas perangkat lunak komputer yang menggunakan kemampuan komputer secara langsung untuk melakukan tugas yang diinginkan dari pemakai. Sehingga dapat disimpulkan bahwa aplikasi dapat membantu manusia dalam melakukan tugas, sesuai dengan sistem yang berjalan di dalam aplikasi tersebut.

\section{Landasan Teori}

\section{Pengertian Sistem Pakar}

Menurut Putri (2016253), sistem pakar (Expert System) adalah salah satu hasil dari perkembangan ilmu komputer, dalam bidang kecerdasan buatan (Artificial Inte/egence), berguna memberikan jalan keluar agar dapat memecahkan masalah tersebut. Sistem yang berusaha meniru pengetahuan dari seorang pakar ke komputer, agar komputer dapat memberikan jalan keluar dari suatu masalah layaknya para pakar.

Menurut Meyliana, Kusrini, dan Luthfi (2016:11), secara umum sistem pakar (Expert System) adalah sistem yang berusaha mengadopsi pengetahuan manusia yang di masukkan ke dalam komputer, agar manusia dapat menyelesaikan masalah sama seperti seorang pakar dalam memecahkan masalah. Sistem pakar membuat seorang awam pun dapat menyelesaikan masalah yang cukup rumit yang sebenarnya hanya dapat diselesaikan dengan bantuan para ahli.

\section{Aplikasi}

Menurut Rubiana, R., \& Arif, M. (2018:261), Aplikasi merupakan suatu subkelas perangkat lunak komputer yang memanfaatkan kemampuan komputer langsung untuk melakukan suatu tugas yang diinginkan pengguna yang mengintegrasikan berbagai kemampuan komputer, tapi tidak secara langsung menerapkan kemampuan tersebut untuk mengerjakan suatu tugas yang menguntungkan pengguna.

Dengan demikian dapat disimpulkan bahwa aplikasi merupakan suatu program komputer yang berisi suatu perintah-perintah yang dapat digunakan untuk membantu manusia dalam mendapatkan suatu hasil yang akurat dan cepat sesuai dengan tujuan pembuatan aplikasi tersebut.

\section{Website}

Menurut Arief (2011:7), Web adalah salah suatu aplikasi yang berisikan dokumen-dokumen multimedia dalam bentuk teks, gambar, animasi, video yang didalamnya menggunakan protocol HTTP (Hypertext Transfer Protokol) dan untuk mengasesnya menggunakan perangkat lunak yang di sebut browser. Dan Website adalah kumpulan dari halaman web yang sudah dipublikasikan di jaringan internet dan memiliki domain/URL (Uniform Resource Locator) yang dapat di akses semua pengguna internet dengan cara mengetik alamatnya. Ada beberapa jenis website yang dikelompokkan berdarkan isinya, diantaranya yaitu:

1. Web Statis, adalah web yang menampilkan suatu informasi dalam bentuk digital baik itu teks, gambar, suara, animasi secara satu arah atau tetap (statis). Disebut satu arah karena pengguna tidak dapat berinteraksi dengan web dan pengguna hanya dapat melihat isi dokumen pada halaman web tersebut.

2. Web Dinamis, adalah web yang menampilkan suatu halaman informasi bentuk digital baik itu teks, gambar, suara, animasi secara dua arah dimana pengguna dapat merubah konten dari halaman web tersebut.

\section{Alat Aplikasi Sistem}

Dalam pengembangan sistem informasi sistem pakar berbasis web ini ada beberapa alat yang digunakan dalam pengembangan sistem aplikasi tersebut, yaitu: bahasa pemrograman menggunakan PHP atau Page Hypertext Preprocessor, database menggunakan MySQL, dan pengaksesan Sistem tersebut menggunakan phpMyAdmin server Apache, dan web browser.

\section{PHP (Hypertext Prepocessor)}

Menurut Sibero dalam Afifah (2017:2), PHP merupakan pemrograman interpreter yaitu proses penerjemahan baris kode sumber menjadi kode mesin yang dimengerti komuter secara Iangsung pada saat 
baris kode dijalankan yang bersifat open source. Berdasarkan pengertian dan penjelasan tersebut dapat diambil kesimpulan bahwa pengertian dari PHP adalah bahasa pemrograman script script yang menyatu dengan HTML untuk membuat halaman web yang bersifar open source juga dapat membuat web menjadi dinamis.

\section{HTML}

Menurut Simarmata dalam Khairuzzaman, M. Q., Nasihin, M., \& Setiawan, H. (2017:47), HTML merupakan singkatan dari Hypertext Markup Language yaitu bahasa markup yang digunakan untuk menyebarkan informasi pada Web, yang kemudian dapat diakses untuk menampilkan berbagai informasi didalam sebuah browser. Ketika merancang HTML, ide ini diambil dari Standard Generalied Markup Language (SGML). Walaupun HTML tidak dengan mudah dapat dipahami kebanyakan orang, ketika diterbitkan penggunanya menjadi jelas. HTML adalah protokol komunikasi stateless yang berbasiskan pada TCP yang awalnya digunakan untuk mengambil kembali file-file HTML dari sewer Web ketika dirancang pada tahun 1991

\section{XAMPP}

Menurut Wicaksono dalam Huda, N. M. (20167), XAMPP merupakan sebuah software yang berfungsi untuk menjalankan website berbasis PHP dan menggunakan pengolahan data MYSQL di komputer local. XAMPP berberan sebagai server web pada komputer dan disebutjuga sebuah Cpane/ Server Virtual, yang dapat membantu melakukan preview sehingga dapat dimotifikasi website tanpa harus online atau terakses ke internet. Software ini merupakan software web server apache yang di dalamnya sudah terdapat database seperti mysql, php, apache, dan lain»lain. Biasanya banyak orang senang menggunakan software web sewer ini karena dalam satu kali install software ini telah sekaligus terinstal Apache Web Server, MySQL Database Sewer, dan PHP Support.

\section{MySQL}

Menurut Wicaksono dalam Huda, N. M. (2016:7), XAMPP merupakan sebuah software yang berfungsi untuk menjalankan website berbasis PHP dan menggunakan pengolahan data MYSQL di komputer local. XAMPP berberan sebagai sewer web pada komputer dan disebut juga sebuah Cpanel Server Virtual, yang dapat membantu melakukan previewsehingga dapat dimodifikasi website tanpa harus online atau terakses ke internet. Software ini merupakan software web server apache yang di dalamnya sudah terdapat database seperti mysql, php, apache, dan Iain-lain. Biasanya banyak orang senang menggunakan software web sewer ini karena dalam satu kali install software ini telah sekaligus terinstal Apache Web Server, MySQL Database Server, dan PHP Support. Dan MySQL merupakan software database yang termasuk popular karena performasi query dari databasenya paling cepat dan jarang bermasalah.

\section{Palawija}

Menurut Indiati (2017:287), Palawija merupakan semua tanaman produktif berkarakter kering yang di tanaman petani pada diantara pergantian musim tanaman padi. Petani menanam palawija untuk mendapatkan hasil tambahan sehingga palawija merupakan tanaman produktif kedua setelah padi. Para petani mempersepsipkan palawija sebagai bahan makanan kedua setelah padi. Palawija merupakan tanaman lain yang di tanam untuk memenuhi kebutuhan pangan penduduk selain tanaman pangan. Sering disebutjuga sebagai tanaman kedua.

Berdasarkan pengeman dan penjelasan tersebut dapat diambil kesimpulan bahwa pengertian dari palawija adalah tanaman pangan kedua pertanian yang di tanam petani disawah atau lading diantara pergantian musim selain tanaman padi yang berkarakter kering.

\section{Hasil \& Implementasi}

\section{Identifikasi dan Analisis Kebutuhan Aplikasi}

Aplikasi yang dibangun merupakan aplikasi yang digunakan untuk memberikan saran kepada petani atau penanam tentang jenis tanaman palawija yang cocok untukdi tanam di daerah mereka. Berdasarkan permasalahan yang di temukan, maka penulis merancang aplikasi berbasis web.Untuk mengetahui jenis tanaman palawija yang cocok, Sistem akan menampilkan berbagai ciri syarat tumbuh dari jenis tanaman palawija yang sudah di rancang penulis sebelumnya. Dan setiap pilihan dari ciri syarat tumbuh jenis tanaman palawija tersebut, maka sistem akan mencocokkan syarat tumbuh dari jenis tanaman palawija tersebut dengan data-data yang tersedia dalam sistem kemudian sistem akan mengeluarkan hasil yang gunanya akan menentukan jenis tanaman palawija apa yang cocok untuk di tanam di daerah mereka masing masing. Dan 
setiap ciri syarat tumbuh jenis tanaman palawija yang penulis berikan melalui sistem adalah melalui beberapa pakar yang telah menuliskan di dalam buku-buku mereka.

\section{Akusisi Pengetahuan}

Dalam sistem yang dirancang oleh penulis terdapat ciri-ciri dari syarat tumbuh yang merupakan pengetahuan yang di kutip dari buku dan penelitian oleh seseorang pakar atau ahli di bidang tanaman jenis palawija. Dari sertiap ciri-ciri syarat tumbuh tanaman palawija bertujuan untuk mengetahui jenis tanaman apa yang cocok di tanam dengan lahan para petani atau penanam. Ada beberapa jenis tanaman palawija di Indonesia menurut Najiyati S, dan Danarti (2012), yaitu Bayam, Gandum, Gembili, Jagung, Kacang hijau, Kacang Panjang, ng tanah, Kacang tunggak, Kedelai, Kentang, Mentimun, Oyong, Selada, Singkong, Sorghum, Talas, Tomat, Ubi jalar, Ubi kayu, Wortel.

\section{Representasi Pengetahuan}

Berdasarkan pengetahuan dan data-data yang didapat dari setiap buku yang penulis telah paparkan di atas, maka penulis merangkumkan nama jenis tanaman palawija beserta ciri-ciri syarat tumbuh dari masingmasing jenis tanaman palawija kedalam bentuk di bawah ini.

Tabel 1 Nama Tanaman Palawija

\begin{tabular}{|l|l|}
\hline Kode & Nama Tanaman Palawija \\
\hline JP001 & Bayam \\
\hline JP002 & Gandum \\
\hline JP003 & Gembili \\
\hline JP004 & Jagung \\
\hline JP005 & Kacang Hijau \\
\hline JP006 & Kacang Panjang \\
\hline JP007 & Kacang Tanah \\
\hline JP008 & Kacang Tungak \\
\hline JP009 & Kedelai \\
\hline JP010 & Kentang \\
\hline JP011 & Mentimun \\
\hline JP012 & Oyong \\
\hline JP013 & Selada \\
\hline JP014 & Singkong \\
\hline JP015 & Sorghum \\
\hline JP016 & Talas \\
\hline JP017 & Tomat \\
\hline JP018 & Ubi Jalar \\
\hline JP019 & Ubi Kayu \\
\hline JP020 & Wortel \\
\hline
\end{tabular}

Tabel 2 Jenis Kriteria

\begin{tabular}{|c|c|}
\hline Kode & Nama Kriteria \\
\hline Kk001 & Ketinggian \\
\hline
\end{tabular}




\begin{tabular}{|c|c|}
\hline Kk002 & Suhu \\
\hline Kk003 & Ph tanah \\
\hline Kk004 & Curah Hujan \\
\hline Kk005 & Intensitas Penyinaran \\
\hline Kk006 & Kelembapan \\
\hline
\end{tabular}

Tabel 3 Subkriteria Ketinggian

\begin{tabular}{|l|l|}
\hline Kode & \multicolumn{1}{|c|}{$\begin{array}{c}\text { Subkriteria } \\
\text { Ketinggian }\end{array}$} \\
\hline Kt01 & $1-800$ \\
\hline Kt02 & $1-900$ \\
\hline Kt03 & $1-1000$ \\
\hline Kt04 & $5-700$ \\
\hline Kt05 & $5-2000$ \\
\hline Kt06 & $10-700$ \\
\hline Kt07 & $10-1500$ \\
\hline Kt08 & $50-500$ \\
\hline Kt09 & $50-500$ \\
\hline Kt010 & $100-500$ \\
\hline Kt011 & $100-1000$ \\
\hline Kt012 & $250-1000$ \\
\hline Kt013 & $400-800$ \\
\hline Kt014 & $500-1000$ \\
\hline Kt015 & $500-1500$ \\
\hline Kt016 & $600-700$ \\
\hline Kt017 & $600-2000$ \\
\hline Kt018 & $1200-1500$ \\
\hline & \\
\hline
\end{tabular}

Tabel 4 Subkriteria Suhu

\begin{tabular}{|l|l|}
\hline Kode & Subkriteria Suhu \\
\hline Sh01 & $15-20 \mathrm{c}$ \\
\hline Sh02 & $15-25 \mathrm{c}$ \\
\hline Sh03 & $15-27 \mathrm{c}$ \\
\hline Sh04 & $17-23 \mathrm{c}$ \\
\hline Sh05 & $18-24 \mathrm{c}$ \\
\hline Sh06 & $18-35 \mathrm{c}$ \\
\hline Sh07 & $20-25 \mathrm{c}$ \\
\hline Sh08 & $20-30 \mathrm{c}$ \\
\hline
\end{tabular}




\begin{tabular}{|l|l|}
\hline Sh09 & $21-27 \mathrm{c}$ \\
\hline Sh10 & $23-27 \mathrm{c}$ \\
\hline Sh11 & $23-34 \mathrm{c}$ \\
\hline Sh12 & $25-27 \mathrm{c}$ \\
\hline Sh13 & $25-30 \mathrm{c}$ \\
\hline Sh14 & $27-32 \mathrm{c}$ \\
\hline Sh15 & $28-32 \mathrm{c}$ \\
\hline
\end{tabular}

Tabel 5 Subkriteria Ph Tanah

\begin{tabular}{|c|}
\hline $\begin{array}{c}\text { Subkriteria } \\
\text { Tanah }\end{array}$ \\
\hline $5,0-6,0$ \\
\hline $5,0-6,5$ \\
\hline $5,0-7,0$ \\
\hline $5,5-6,5$ \\
\hline $5,5-70$ \\
\hline $6,0-6,5$ \\
\hline $6,0-7,0$ \\
\hline
\end{tabular}

Tabel 6 Subkriteria Curah Hujan

\begin{tabular}{|l|l|}
\hline \multicolumn{1}{|c|}{ Kode } & Subkriteria Curah Hujan \\
\hline Ch01 & $50-70 \mathrm{~mm} /$ bulan \\
\hline Ch02 & $50-80 \mathrm{~mm} /$ bulan \\
\hline Ch03 & $50-125 \mathrm{~mm} /$ bulan \\
\hline Ch04 & $50-200 \mathrm{~mm} /$ bulan \\
\hline Ch05 & $60-100 \mathrm{~mm} /$ bulan \\
\hline Ch06 & $60-125 \mathrm{~mm} /$ bulan \\
\hline Ch07 & $65-110 \mathrm{~mm} /$ bulan \\
\hline Ch08 & $65-165 \mathrm{~mm} /$ bulan \\
\hline Ch09 & $70-150 \mathrm{~mm} /$ bulan \\
\hline Ch10 & $80-165 \mathrm{~mm} /$ bulan \\
\hline Ch11 & $80-170 \mathrm{~mm} /$ bulan \\
\hline Ch12 & $80-210 \mathrm{~mm} /$ bulan \\
\hline Ch13 & $85-200 \mathrm{~mm} /$ bulan \\
\hline Ch14 & $100-200 \mathrm{~mm} /$ bulan \\
\hline Ch15 & $125-160 \mathrm{~mm} /$ bulan \\
\hline Ch16 & $155-160 \mathrm{~mm} /$ bulan \\
\hline Ch17 & $160-250 \mathrm{~mm} /$ bulan \\
\hline
\end{tabular}




\begin{tabular}{|l|l|}
\hline Ch18 & $200-400 \mathrm{~mm} /$ bulan \\
\hline
\end{tabular}

Tabel 7 Subkriteria Intensitas Penyinaran

\begin{tabular}{|l|l|}
\hline Kode & Subkriteria Intensitas Penyinaran \\
\hline Ip01 & $8-12$ jam / hari \\
\hline Ip02 & $9-10$ jam / hari \\
\hline Ip03 & $9-11$ jam / hari \\
\hline Ip04 & $9-12$ jam / hari \\
\hline Ip05 & $10-11$ jam / hari \\
\hline Ip06 & $10-12$ jam / hari \\
\hline Ip07 & $11-12$ jam / hari \\
\hline
\end{tabular}

Tabel 8 Subkriteria Kelembaban

\begin{tabular}{|l|c|}
\hline Kode & $\begin{array}{c}\text { Subkriteria } \\
\text { Kelembaban }\end{array}$ \\
\hline Kb01 & $20-40 \%$ \\
\hline Kb02 & $50-60 \%$ \\
\hline Kb03 & $50-70 \%$ \\
\hline Kb04 & $50-80 \%$ \\
\hline Kb05 & $50-85 \%$ \\
\hline Kb06 & $55-65 \%$ \\
\hline Kb07 & $60-65 \%$ \\
\hline Kb08 & $65-75 \%$ \\
\hline Kb09 & $70-80 \%$ \\
\hline Kb10 & $75-85 \%$ \\
\hline Kb11 & $80-90 \%$ \\
\hline Kb12 & $85-90 \%$ \\
\hline
\end{tabular}

\section{Penjelasan Alur Algoritma}

Pada aplikasi yang akan di bangun algoritma yang digunakan adalah menggunakan metode If- else. Metode ini merupakan metode yang menggunakan kondisi-aksi yang telah ditentukan berdasarkan data-data dan pengetahuan yang telah diperoleh sebagai aturan alur mana yang dijalankan atau dilewati. Sustem ini melakukan identifikasi dengan cara if-else yaitu dengan bergerak maju secara terus menerus dari simpul yang ada sesuai dengan data dan akan pindah ke tingkat selanjutnya jika alur yang dilewati terpenuhi, dengan kata lain kondisi tersebut terpenuhi. Kondisi tersebut didahului dengan ketinggian berada di posisi pertama berikutnya suhu, ph tanah, curah hujan, intensitas penyinaran, dan barulah kelembaban. Kemudian aturan tersebut dijalankan sampai di temukan suatu hasil. Implementasi metode if-else pada sistem ini adalah mendapatkan fakta- fakta karakteristik syarat tumbuh tanaman palawija. Dari fakta-fakta karakteristik tersebut maka akan dihasilkan suatu kesimpulan tanaman palawija apa yang cocok untuk ditanam.

Berikut adalah contoh dari metode forward chaining. IF ketinggian 400 mdpl AND suhu 25 c AND ph tanah 7.0 AND curah hujan $100 \mathrm{~mm} /$ bulan AND intensitas penyinaran 10 jam jam/hari AND kelembaban $60 \%$ THEN Bayam.

Tabel 9 Pembentukan rule if-else 


\begin{tabular}{|c|c|}
\hline \multicolumn{1}{|c|}{ If } & Then \\
\hline Kt05,Sh08,Ph07,Ch10,Ip06,Kb06 & Bayam (JP001) \\
\hline Kt13,Sh07,Ph07,Ch01,Ip04,Kb11 & Gandum (JP002) \\
\hline Kt02,Sh11,Ph02,Ch09,Ip02,Kb11 & Gembili (JP003) \\
\hline Kt09,Sh10,Ph05,Ch13,Ip06,Kb10 & Kacang Hijau (JP005) \\
\hline Kt04,Sh12,Ph04,Ch04,Ip02,Kb04 & Kacang Panjang (JP006) \\
\hline Kt16,Sh08,Ph04,Ch03,Ip01,Kb03 & Kacang Tanah (JP007) \\
\hline Kt08,Sh15,Ph06,Ch07,Ip04,Kb08 & Kacang Tunggak (JP008) \\
\hline Kt15,Sh13,Ph04,Ch02,Ip04,Kb09 & Kedelai (JP009) \\
\hline Kt10,Sh10,Ph04,Ch14,Ip06,Kb09 & Mentimum (JP011) \\
\hline Kt17,Sh07,Ph02,Ch18,Ip04,Kb11 & Oyong (JP012) \\
\hline Kt03,Sh12,Ph07,Ch18,Ip01,Kb11 & Selada (JP013) \\
\hline Kt03,Sh05,Ph04,Ch17,Ip06,Kb02 & Singkong (JP014) \\
\hline Kt17,Sh02,Ph02,Ch11,Ip06,Kb03 & Sorghum (JP015) \\
\hline Kt07,Sh,03,Ph04,Ch15,Ip03,Kb07 & Talas (JP016) \\
\hline Kt01,Sh14,Ph03,Ch01,Ip06,Kb01 & Tomat (JP017) \\
\hline Kt12,Sh13,Ph04,Ch16,Ip05,Kb07 & Ubi Jalar (JP018) \\
\hline Kt11,Sh04,Ph01,Ch05,Ip06,Kb12 & Ubi Kayu (JP019) \\
\hline Kt14,Sh09,Ph07,Ch06,Ip07,Kb07 & Wortel (JP020) \\
\hline Kt06,Sh06,Ph03,Ch12,Ip02,Kb07 & \\
\hline Kt18,Sh01,Ph04,Ch08,Ip02,Kb11 & \\
\hline
\end{tabular}

\section{Analisis Kebutuhan Sistem}

Aplikasi mengidentifikasi jenis tanaman palawija menggunakan algoritma Forward chaining berbasis Web ini mengadopsi cara seorang pakar berpikir. Dalam merancang sistem ini, ada beberapa fungsi yang dibutuhkan sebagai berikut:

1. Para petani atau penanam dapat memilih kriteria syarat tumbuh.

2. Para petani atau penanam dapat melihat hasil dari tanaman yang cocok.

3. Para petani atau penanam dapat melihat daftar dari tanaman palawija.

\section{Flowchart}

Menurut Mujono dalam Prawiyanti, A. A. (2013:45), Flowchart adalah gambaran atau bagan yang memperlihatkan urutan dan hubungan antar proses beserta instruksinya. Pengertian flowchart adalah representasi grafik yang menggambarkan setiap langkah yang akan dilakukan dalam suatu proses, yang merupakan alat bantu yang banyak digunakan untuk menggambarkan sistem secara pisikal. 


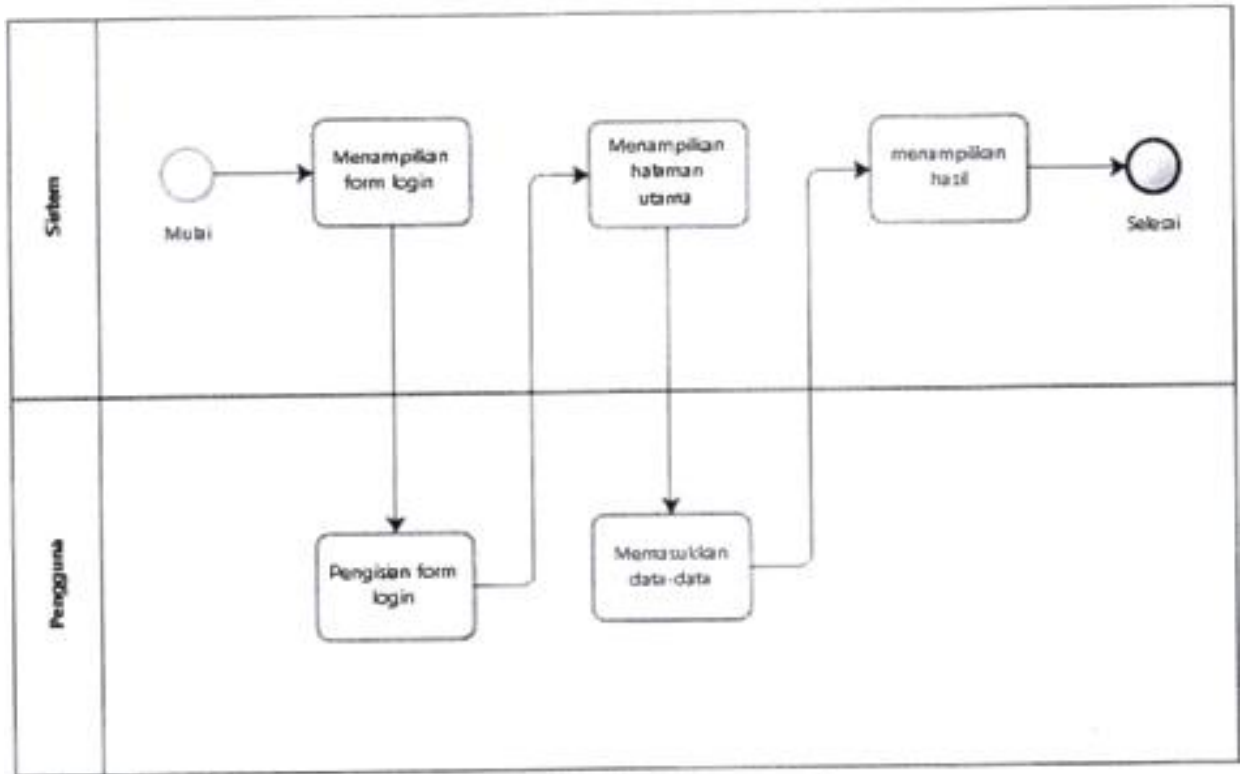

Gambar 1 Flowchart Perancangan Sistem

\section{Use Case Diagram}

Use case diagram adalah untuk memodelkan proses kerja pada suatu sistem aplikasi. Use case diagram seperti Gambar 2, menunjukkan fungsi-fungsi apa saja yang dapat dilakukan oleh pengguna.

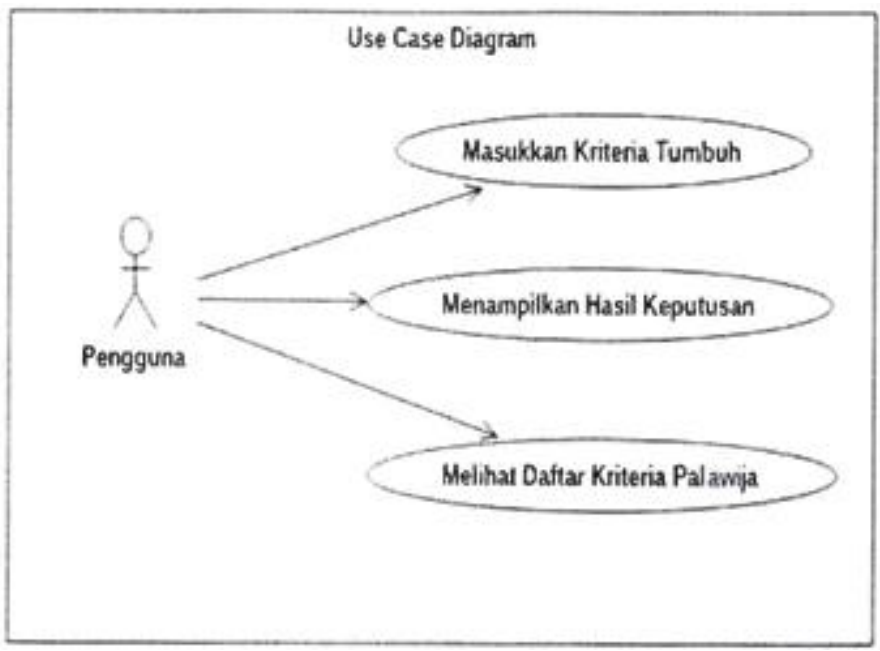

Gambar 2 Use Case Diagram berikut:

Dari gambar 2 Use Case Diagram diatas, dapat dijelaskan fungsi-fungsi yang dapat dilakukan sebagai

1. Masukkan Kriteria Tumbuh. Memilih kriteria tumbuh adalah proses di mana pengguna memasukkan syarat tumbuh tanaman palawija yang pengguna ketahui sesuai dengan daerah atau lahan mereka sehingga pengguna mendapatkan hasil berdasarkan sistem.

2. Menampilkan Hasil Keputusan. Menampiikan hasil keputusan adalah proses dimana pengguna mendapatkan hasil keputusan tanaman palawija yang cocok dari proses memasukkan kriteria syarat tumbuh.

3. Menampilkan Daftar Kriteria Palawija. Menampilkan daftar kriteria palawija adalah proses di mana pengguna dapat melihat informasi dari tanaman palawija di Indonesia dan syarat tumbuh dari tanaman palawija tersebut.

\section{Activity Diagram}


Activity diagram menjelaskan bagaimana proses atau alur kerja sistem informasi dari suatu aplikasi

\section{Activity Diagram Halaman Utama}

Diagram ini menjelaskan proses atau alur kerja di halaman Utama. Pertama-tama pengguna membuka halam Utama dari sistem. Kemudian pengguna harus memasukkan username atau nama dari pengguna untuk dapat masuk kedalam aplikasi tersebut.

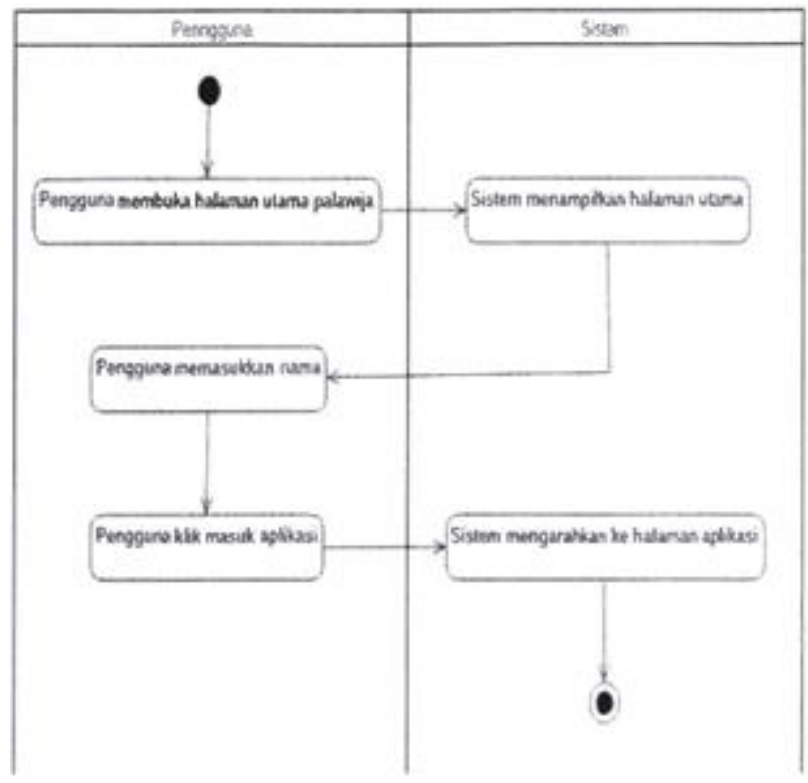

Gambar 3 Activity Diagram Halaman Utama

\section{Activity Diagram Kriteria}

Diagram ini menjelaskan proses memilih kriteria syarat tumbuh dari tanaman palawija. Dalam diagram ini pengguna memasukkan kriteria yang teleh disediakan dari tanaman menurut daerah atau Iahan yang akan mereka tanam. Jika pengguna sudah mengisi kriteria dengan lengkap maka sistem akan menampilkan halaman hasil dan pengguna akan mendapatkan hasil tanaman yang cocok berdasarkan kriteria yang telah mereka input.

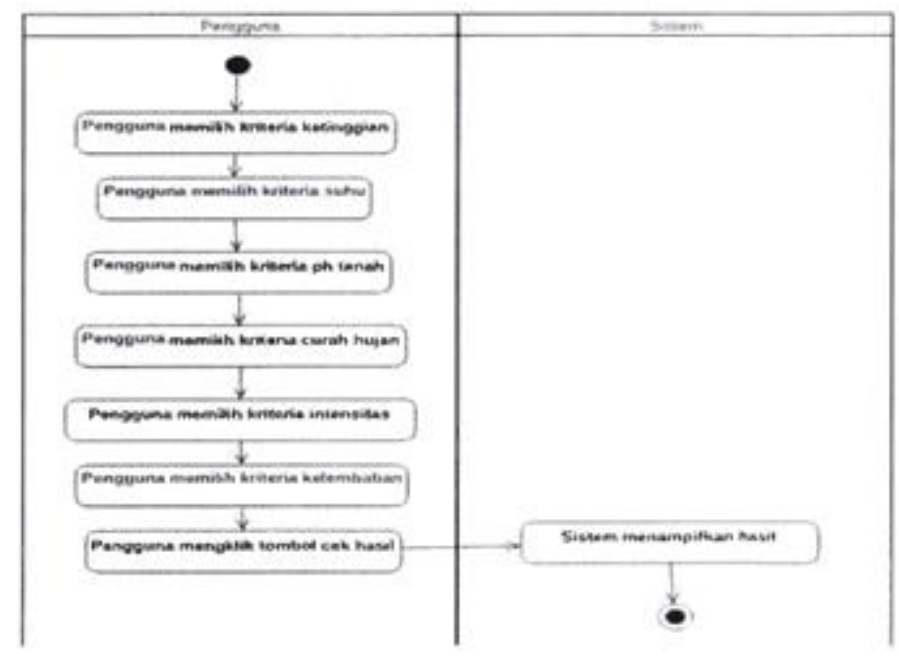

Gambar 4 Activity Diagram Kriteria

\section{Activity Diagram Daftar Palawija}

Diagram ini menjelaskan proses menampilkan daftar jenis tanaman palawija. Pada proses ini pengguna dapat melihat daftar jenis tanaman palawija dan syarat tumbuh dari tanaman palawija tersebut. Pertama- tama 
pengguna mengklik tombol daftar palawija, selanjutnya sistem akan menampilkan halaman daftar tanaman palawija.

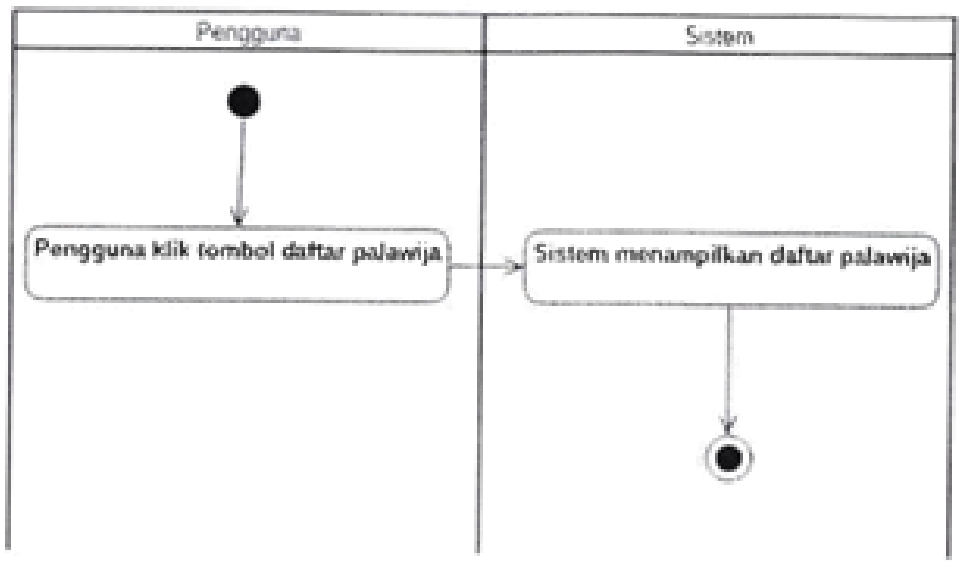

Gambar $\overline{\mathbf{5}}$ Activity Diagram Palawija

\section{Kamus Data}

Kamus data adalah katalog dari data dan kebutuhan informasi dari suatu sistem informasi di dalam database dan hubungan antara table yang dibuat berbentuk tabel di dalam sebuah basis data

Tabel 10 Kamus Data

\begin{tabular}{|c|c|c|c|}
\hline Nama Tabel & Nama Field & Tipe Data & Key \\
\hline User & nama_user & varchar(30) & Fk tbl_hasil \\
\hline \multirow[t]{3}{*}{ Tanaman } & kode_tanaman & varchar(15) & $\begin{array}{c}\text { Primary key, } F k \\
\text { tbl_hasil }\end{array}$ \\
\hline & nama_tanaman & varchar(20) & \\
\hline & kode_kriteria & varchar(15) & \\
\hline \multirow[t]{3}{*}{ Kriteria } & kode_kriteria & varchar(15) & $\begin{array}{r}\text { Primary } k e y, \quad F k \\
\text { tbl_tanaman }\end{array}$ \\
\hline & nama_kriteria & varchar(20) & \\
\hline & kode_subkriteria & varchar(15) & Fk tbl_kriteria \\
\hline \multirow[t]{3}{*}{ Subkriteria } & kode_subkriteria & varchar(15) & $\begin{array}{l}\text { Primary Key, } F K \\
\text { tbl_kriteria }\end{array}$ \\
\hline & nama_subkriteria & varchar(20) & \\
\hline & kode_kriteria & varchar(25) & FK tbl_kriteria \\
\hline \multirow[t]{7}{*}{ Hasil } & nama_user & varchar(30) & $F k$ tbl_user \\
\hline & kode_tanaman & varchar(15) & $\begin{array}{r}\text { Primary } K e y, \quad F K \\
\text { tbl_tanaman }\end{array}$ \\
\hline & nama_tanaman & varchar(20) & \\
\hline & ketinggian & varchar(30) & \\
\hline & Suhu & varchar(30) & \\
\hline & ph_tanah & varchar(30) & \\
\hline & curah_hujan & varchar(30) & \\
\hline
\end{tabular}




\begin{tabular}{|l|l|l|l|}
\hline & intensitas_cahaya & varchar(30) & \multirow{2}{*}{ varchar(30) } \\
\cline { 2 - 3 } & kelembaban & \multicolumn{1}{|c|}{} \\
\hline
\end{tabular}

\section{Hasil Dan Pembahasan}

Hasil perancangan

Hasil dari perancangan aplikasi ini adalah sebuah saran dari tanaman palawija yang cocok menurut analisa yang sudah dilakukan sebelumnya. Adapun hasil rancangan aplikasi sebagai berikut:

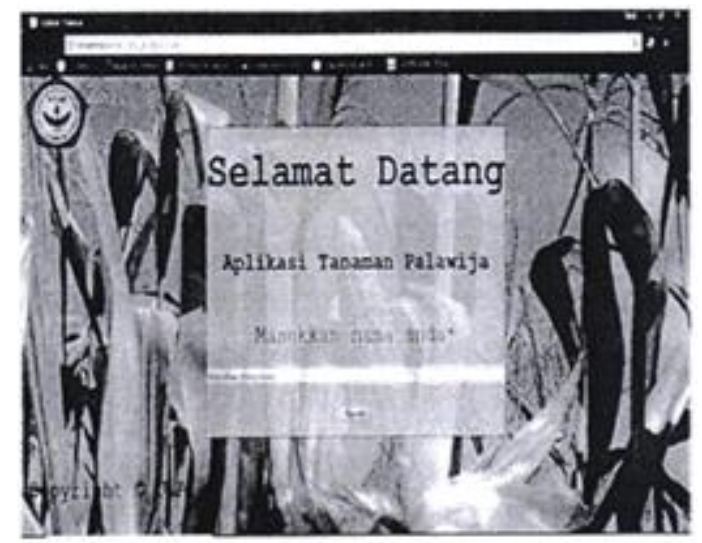

Gambar 6 Halaman Login

\section{Halaman Login}

Untuk mengakses aplikasi pada website, user atau pengguna terlebih dahulu akan memasukkan nama pada halaman login. Setelah pengguna mengisi form masukkan nama selanjutnya pengguna akan di arahkan ke halaman utama dari aplikasi tanaman palawija. Apabila pengguna tidak memasukkan nama maka aka nada pemberitahuan bahwa form harus diisi. Untuk halaman login dari aplikasi tanaman palawija ini dapat dilihat pada Gambat 6 di atas.

\section{Halaman Utama}

Halaman utama adalah tampilan yang berisi sebuah pesan selamat datang kepada pengguna yang sudah melakukan login ke dalam aplikasi tanaman palawija. Apabila pengguna sudah berhasil masuk pada halaman utama ini, pengguna sudah dapat menggunakan fitur pada aplikasi ini secara keseluruhan, sesuai dengan hak pengguna masingvmasing, Pada halaman ini terdapat sebuah sidebar menu yang menampilkan pilihan menu Home, About, Aplikasi, dan Daftar Palawija. Tampilan halaman utama dapat dilihat pada gambar 7 di bawah ini.

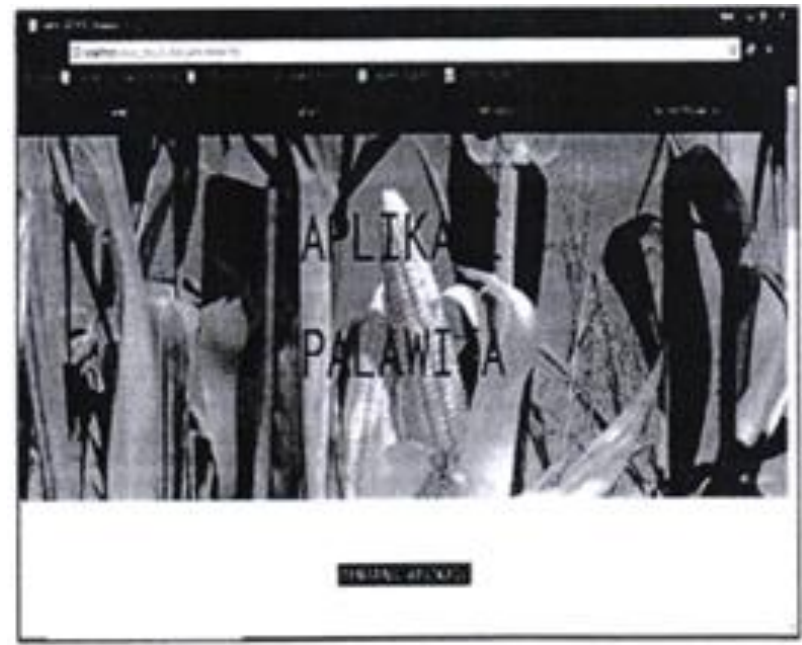

\section{Halaman About}

Gambar 7 Tampilan Halaman Utama 
Halaman About adalah halaman yang digunakan menginformasikan kepada pengguna atau user tentang aplikasi tanaman dan bagaimana cara menggunakan aplikasi. Agar pengguna dapat menggunakan aplikasi dengan benar. Tampilan halaman about dapat dilihat pada Gambar 8 di bawah Ini

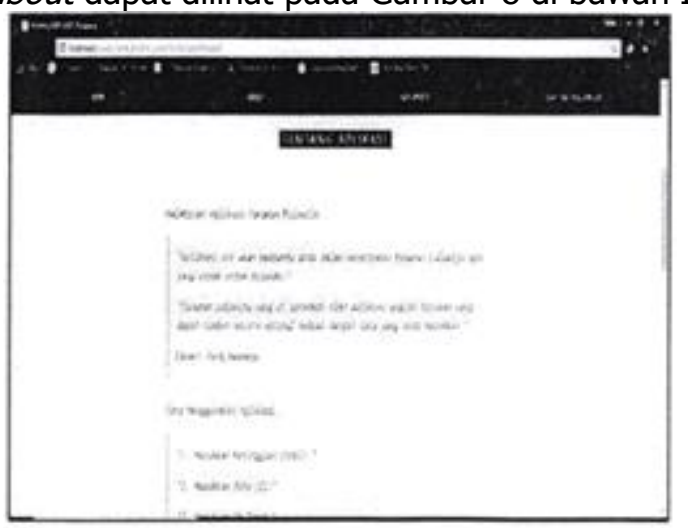

Gambar 8 Tampilan Halaman About

\section{Halaman Aplikasi}

Halaman Aplikasi adalah halaman yang digunakan menggunakan aplikasi. Pada halaman ini pengguna atau user mengisi kriteria-kriteria yang telah disediakan didalam aplikasi sesuai dengan kriteria yang diinginkan. Setelah itu jika sudah terisi semua maka pengguna harus mengklik tombol cari hasil untuk dapat meiihat tanaman apa yang cocok di tanam. Tampilan halaman aplikasi kategori dapat dilihat pada Gambar 9.

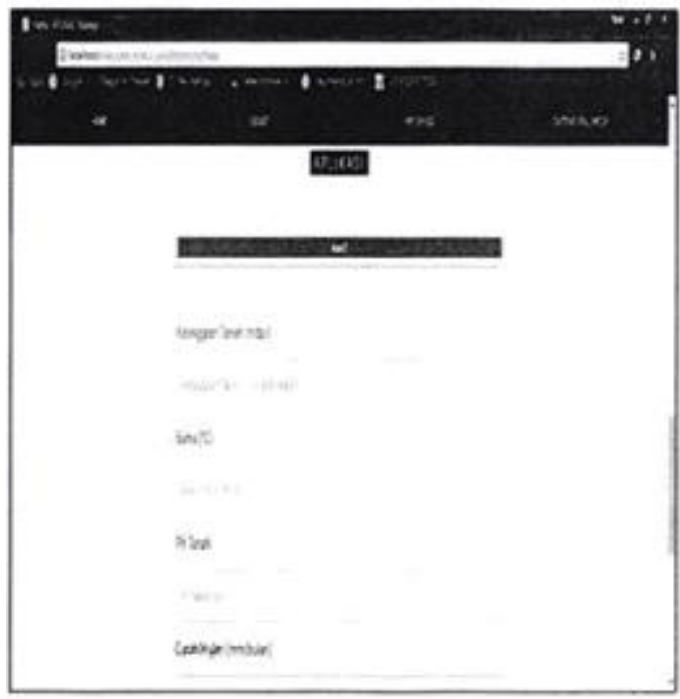

Gambar 9 Tampilan Halaman Aplikasi

\section{Halaman Daftar Palawija}

Halaman daftar palawija adalah halaman yang digunakan untuk melihat data-data dari tanaman palawija beserta karakteristik syarat tumbuh dari tanaman palawija tersebut. Tampilan halaman daftar palawija dapat dilihat pada Gambar 10 di bawah ini 


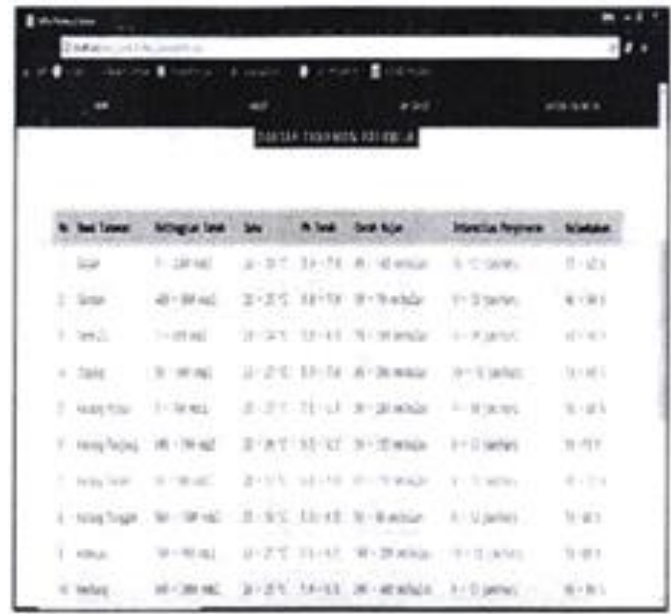

Gambar 10 Tampilan Halaman Daftar Palawija

\section{Halaman Hasil}

Halaman hasil adalah halaman yan akan keluar ketika pengguna mengklik tombol cari hasil halaman ini dan halaman ini digunakan untuk menampilkan hasil dari tanaman yang cocok untuk ditanam. Hasil tersebut diperoleh dari data-data pengguna atau user yang sudah memasukkan karakteristik dari syarat tumbuh yang telah disediakan di halaman aplikasi. Tampilan hasil dapat dilihat pada Gambar 11 di bawah.

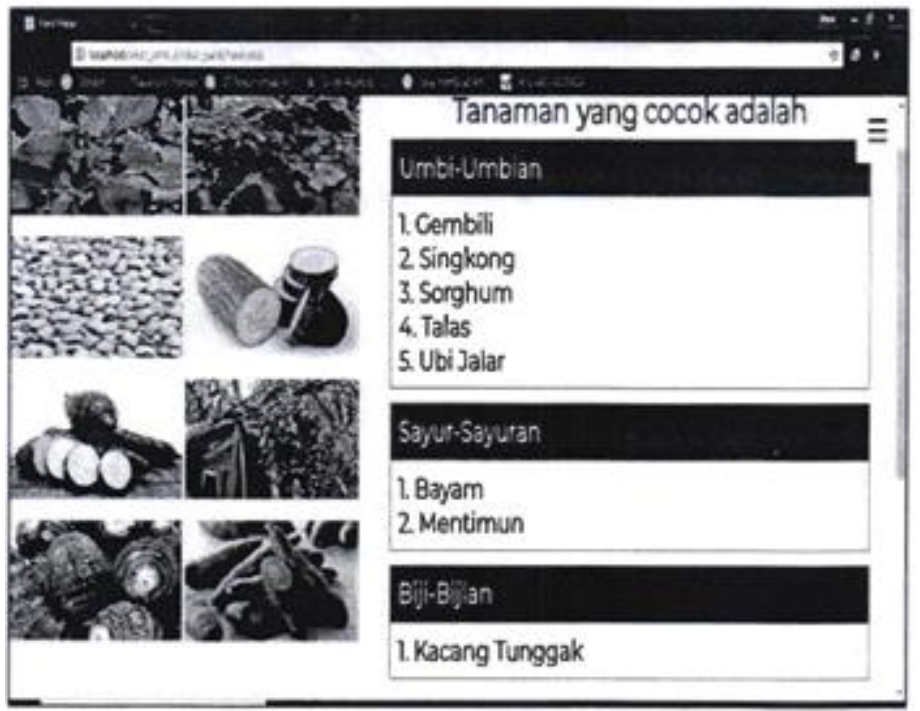

Gambar 11 Tampilan Halaman Hasil

\section{Pengujian Aplikasi}

Tahap pengujian sistem in berguna untuk mengurangi bahkan menghilangkan kesalahan pada sistem tersebut. Untuk mengetahui apakah sistem tersebut telah mencapai tujuan yang diharapkan sehingga dapat dijadikan solusi dari permasalahan yang ada. Maka pada penelitian ini dilakukan sebuah pengujian aplikasi dengan menggunakan pengujian black box. Pengujian Black box berkaitan dengan pengujian-pengujian yang dilakukan pada antarmuka perangkat lunak yang telah dirancang. Pengujian dilakukan untuk mengetahui kemampuan sistem dalam menangani beberapa kondisi. Dari hasil pengujian yang telah dilakukan, menghasilkan penilaian bahwa sistem layak untuk dipergunakan. Hasil pengujian blackbox aplikasi tanaman palawija dapat dilihat sebagai berikut:

\section{Tabel Pengujian BlackBox}

Berdasarkan hasil pengujian black box yang sudah dilakukan oleh penulis, maka dibuat sebuah tabel pengujian, hasil pengujian black box dapat dilihat pada tabel sebagai berikut: 
Tabel 11 Pengujian BlackBox Aplikasi Tanaman Palawija

\begin{tabular}{|c|c|c|c|c|c|}
\hline No & Form & $\begin{array}{r}\text { Data } \\
\text { Masukan }\end{array}$ & $\begin{array}{c}\text { Data } \\
\text { Diharapkan }\end{array}$ & Hasil & Kesimpulan \\
\hline \multicolumn{6}{|c|}{ Kasus dan Hasil Uji (Data Normal) } \\
\hline 1 & Login & $\begin{array}{l}\text { Melakukan } \\
\text { login }\end{array}$ & $\begin{array}{c}\text { Masuk ke } \\
\text { dalam aplikasi } \\
\text { dengan } \\
\text { memasukkan } \\
\text { nama pengguna } \\
\text { atau user }\end{array}$ & $\begin{array}{r}\text { Masuk ke } \\
\text { dalam aplikasi } \\
\text { dengan nama } \\
\text { pengguna }\end{array}$ & OK \\
\hline \multicolumn{6}{|c|}{ Kasus dan Hasil Uji (Data Salah) } \\
\hline 2 & Login & $\begin{array}{l}\text { Form kosong } \\
\text { atau tidak diisi }\end{array}$ & $\begin{array}{l}\text { Menampilkan } \\
\text { pesan selamat } \\
\text { datang }\end{array}$ & $\begin{array}{l}\text { Menampilkan } \\
\text { pesan "Please fill } \\
\text { out this field" }\end{array}$ & OK \\
\hline \multicolumn{6}{|c|}{ Kasus dan Hasil Uji (Data Normal) } \\
\hline 3 & Home & $\begin{array}{l}\text { Menekan } \\
\text { tombol navigasi } \\
\text { home }\end{array}$ & $\begin{array}{l}\text { Menampilkan } \\
\text { pesan selamat } \\
\text { datang }\end{array}$ & $\begin{array}{l}\text { Menampilkan } \\
\text { pesan selamat } \\
\text { datang }\end{array}$ & OK \\
\hline \multicolumn{6}{|c|}{ Kasus dan Hasil Uji (Data Normal) } \\
\hline 4 & About & $\begin{array}{c}\text { Menekan } \\
\text { tombol navigasi } \\
\text { About }\end{array}$ & $\begin{array}{l}\text { Menampilkan } \\
\text { informasi tentang } \\
\text { penggunaan } \\
\text { aplikasi }\end{array}$ & $\begin{array}{l}\text { Menampilkan } \\
\text { informasi tentang } \\
\text { penggunaan } \\
\text { aplikasi }\end{array}$ & OK \\
\hline \multicolumn{6}{|c|}{ Kasus dan Hasil Uji (Data Normal) } \\
\hline 5 & Aplikasi & $\begin{array}{l}\text { Memasukkan } \\
\text { data syarat } \\
\text { tumbuh ke dalam } \\
\text { aplikasi }\end{array}$ & $\begin{array}{l}\text { Menampilkan } \\
\text { hasil berdasarkan } \\
\text { data yang } \\
\text { dimasukkan }\end{array}$ & $\begin{array}{l}\text { Menampilkan } \\
\text { hasil berdasarkan } \\
\text { data yang di } \\
\text { masukkan }\end{array}$ & OK \\
\hline \multicolumn{6}{|c|}{ Aplikasi dan Hasil Uji (Data Normal) } \\
\hline
\end{tabular}




\begin{tabular}{|c|c|c|c|c|c|}
\hline 6 & $\begin{array}{c}\text { Menekan } \\
\text { Daftar } \\
\text { palawija }\end{array}$ & $\begin{array}{c}\text { Menampilkan } \\
\text { tombol navigasi } \\
\text { daftar palawija } \\
\text { tabel data } \\
\text { informasi } \\
\text { tanaman palawija }\end{array}$ & $\begin{array}{c}\text { Menampilkan } \\
\text { tabel data } \\
\text { informasi } \\
\text { tanaman palawija }\end{array}$ & OK \\
\hline
\end{tabular}

\section{Kesimpulan Pengujian BlackBox}

Berdasarkan hasil pengujlan dengan kasus blackbox dengan melihat fungsionalitas yang ada pada aplikasi dapat diambil kesimpulan bahwa Sistem sudah dapat menjalankan fungsi-fungsi, dan interface dengan baik. Dan secara fungsional sistem dapat mengeluarkan hasil yang sesuai dengan yang diharapkan. Sistem juga sudah dapat menangani data masukan salah dan benar dengan menghasilkan output yang diharapkan.

\section{Kesimpulan}

Setelah melakukan perancangan dan melakukan evaluasi terhadap aplikasi yang sudah dibuat, maka penulis mengambil kesimpulan sebagai berikut:

1. Aplikasi ini dapat diterapkan pada aplikasi website.

2. Aplikasi ini dapat memberikan informasi tentang tanaman palawija apa yang cocok ditanam pada lahan tertentu, berdasarkan jawaban atas pertanyaan pertanyaan yang diajukan oleh aplikasi ini.

\section{Referensi}

1. Afifah, I. I. N. (2017). Sistem Informasi Penjualan Busana Pengantin Pada Tutut Manten Yogyakarta. Speed-Sentra Penelitian Engineering dan Edukasi, 10(1).

2. Arief, M. Rudyanto. 2011. Pemrograman Web Dinamis Menggunakan PHP \& MySQL. Yogyakarta:ANDI

3. Hidayati, N., \& Hadi, S. (2017). Analisa Dan Perancangan Sistem Informasi Akademik Dan Keuangan Online Pada Perguruan Tinggi. SINTAK, 1.

4. Huda, N. M. (2016). LKP: Rancang Bangun Aplikasi Penjadwalan Mata Pelajaran Pada SMA

Shafta Surabaya (Doctoral dissertation, Institut Bisnis dan Informatika Stikom Surabaya).

5. Indiati, S. W., \& Marwoto, M. (2017). Penerapan Pengendalian Hama Terpadu (PHT) pada Tanaman Kedelai. Buletin Palawija, 15(2), 87-100.

6. Khairuzzaman, M. Q., Nasihin, M., \& Setiawan, H. (2017). Perancangan Sistem Penjualan Batu Permata Berbasis Web Pada Toko Batu Permata Dan Mulia Redha Collection. Konferensi Nasional Sosial \& Teknologi, 1(1).

7. Meyliana, A., Kusrini, \& Luthfi, E. T. (2016). Sistem Pakar Pada Konsultasi Jenis Senam Dengan Metode Forward Chaining. Jurnal Informa Politeknik Indonusa Surakarta ISSN : 2442-7942 Vol. 1 Nomor 3.

8. Putri, N. E. (2016). Sistem Pakar Kerusakan Hardware Komputer Dengan Metode Forward Chaining. Jurnal Momentum, 53.

9. Sundawa, A. (2018). Perancangan Bangun Sistem Penjadwalan Acara Keluarga Mahasiswa Teknik Informatika (KMTI) Di Universitas Muhammadiyah Yogyakarta Berbasis Android dissertation, FT UMY). 